\title{
Artificial Neural Network Modeling for Al-Zn-Sn Sacrificial Anode protection of Low Carbon Steel in Saline Media
}

\author{
O. Oluwole ${ }^{*}$, N. Idusuyi \\ Department of Mechanical Engineering, University of Ibadan, Nigeria
}

\begin{abstract}
This work presents the artificial neural network(ANN) modeling for sacrificial anode cathodic protection of low carbon steel using Al-Zn-Sn alloys anodes in saline media. Corrosion experiments were used to obtain data for developing a neural network model. The Feed forward Levenberg-Marquadt training algorithm with passive time, $\mathrm{pH}$, conductivity, \% metallic composition used in the input layer and the corrosion potential measured against a silver/silver chloride $(\mathrm{Ag} / \mathrm{AgCl})$ reference electrode used as the target or output variable. The modeling results obtained show that the network with 4 neurons in the input layer, 10 neurons in the hidden layer and 1 neuron in the output layer had a high correlation coefficient (R-value) of 0.850602 for the test data, and a low mean square error (MSE) of 0.0261294. 9
\end{abstract}

Keywords Cathodic Protection, Sacrificial Anodes, Artificial Neural Networks

\section{Introduction}

Corrosion is the destruction of material resulting from exposure and interaction with the environment[1]. While common usage typically associates corrosion with metals, the destruction of non-metallic materials as a result of exposure to sunlight can be considered as corrosion[1]. The economic cost of corrosion was estimated some years ago by the US Department of Commerce to be approximately $5 \%$ of the Gross National Product[2]. However corrosion not only has an economic cost it can present a threat to life through the collapse of a structure or to the environment through the leak of toxic chemicals[3]. To control corrosion effectively, the accurate modeling and prediction of corrosion behaviour is a fundamental requirement[4]. Artificial neural networks are computational systems that simulate the Neurons or simple processors of a biological nervous system and have been used to solve complex engineering problems like corrosion $[4,5]$. Basically, all ANNs have a similar topological structure or architecture[5]. The interaction of the neurons in the network is roughly based on the principles of neural science. The neural network can learn both static and dynamic properties autonomously based on the past history of the measurement data and then act in such a way that a better solution can be obtained under unknown environmental conditions. Hence they are suitable for problems where pattern

* Corresponding author:

oluwoleo2@asme.org (O. Oluwole)

Published online at http://journal.sapub.org/materials

Copyright (C) 2012 Scientific \& Academic Publishing. All Rights Reserved recognition is important and precise computational answers are not required $[4,5]$.

Different researchers have attempted at various times to deploy the neural network technique for the prediction of corrosion rate, which have yielded very good prediction results compared to mechanistic models[4,5,8].

$\mathrm{Yu}$ Sun et al[9] studied the microstructure-property relationship of a titanium (Ti-6Al-4V) alloy with Artificial neural networks. His results showed very good agreements between experimental and ANN model. Tomislav Rolic et al[10] estimated the corrosion of steel guitar strings in the artificial sweat solution using neural networks. From measurements and training results a high correlation coefficient and low mean absolute error between measured and estimated output values were observed. As opposed to a deterministic approach corrosion potential data (polarization curves) on metallic glasses, corrosion rate and weight loss data on carbon and alloy steel and crevice corrosion data on grade-2 titanium have been used for comparison and future prediction of the alloys' corrosion behavior using ANN[11, 12].

Artificial neural networks have also found increasing usage along side mechanistic approaches in determining evolution of corrosion rate and yield strength in certain Mg-Rare Earth alloys[13] and modeling pit growths in high strength aluminum alloys[14].

However, some of these applications are advanced modeling techniques that are not readily available to the corrosion engineer who may be interested in creating his/her own neural network model for the corrosion problem at hand. Hence this paper seeks to demonstrate an attempt to create a 
successful neural network model for an Al-Zn-Sn sacrificial anode protection system using a simple and straightforward modeling strategy.

\section{Materials and Method}

\subsection{Material}

The chemical composition of the low carbon steel sample used is presented in Table 1. The cast aluminum anodes used were $\mathrm{Al}-\mathrm{Zn}(5 \%)-\mathrm{Sn}(0.1 \%), \mathrm{Al}-\mathrm{Zn}(7 \%)-\mathrm{Sn}(0.1 \%)$ and $\mathrm{Al}-$ $\mathrm{Zn}(10 \%)-\operatorname{Sn}(0.1 \%)$.

In this work, the Levenberg-Marquadt training algorithm was used to develop a network for predicting the corrosion potential of low carbon steel in saline media. Corrosion experiments were mounted to obtain the necessary data for training the networks.

\subsection{Methods}

\subsubsection{Preparation of Samples}

The low carbon steel specimen with dimensions of $50 \mathrm{~mm}$ x $50 \mathrm{~mm} \times 1 \mathrm{~mm}$ (eight pieces) were neatly cut and polished in a sequence of emery papers until a smooth finish was obtained. They were cleaned by rinsing under running tap water, distilled water and acetone. This was done a number of times to ensure that there were no traces of corrosion products on the metal surface

Table 1. Chemical composition of low carbon steel

\begin{tabular}{|c|c|}
\hline Element & \% Composition \\
\hline $\mathrm{C}$ & 0.0329 \\
\hline $\mathrm{Si}$ & 0.0077 \\
\hline $\mathrm{S}$ & 0.0186 \\
\hline $\mathrm{P}$ & 0.0109 \\
\hline $\mathrm{Mn}$ & 0.2918 \\
\hline $\mathrm{Ni}$ & 0.0209 \\
\hline $\mathrm{Cr}$ & 0.0182 \\
\hline $\mathrm{Mo}$ & 0.004 \\
\hline $\mathrm{V}$ & 0.0011 \\
\hline $\mathrm{Cu}$ & 0.0405 \\
\hline $\mathrm{W}$ & 0.0065 \\
\hline $\mathrm{Co}$ & 0.0025 \\
\hline $\mathrm{Al}$ & 0.0172 \\
\hline $\mathrm{Pb}$ & 0.0072 \\
\hline $\mathrm{Zn}$ & 0.0049 \\
\hline $\mathrm{Fe}$ & 99.5268 \\
\hline
\end{tabular}

\subsubsection{Experimental Data}

Electrochemical measurements were carried out on the low carbon steel specimens with $25 \mathrm{~cm}^{2}$ exposed geometric surface, protected with the aluminum alloy anodes immersed in $1 \mathrm{M}$ and $0.5 \mathrm{M} \mathrm{NaCl}$ solutions. The potentials were measured against an $\mathrm{Ag} / \mathrm{AgCl}$ saturated reference electrode using a DT9205A digital multimeter. All measurements were carried out at a temperature of $298 \mathrm{~K}$. The $\mathrm{pH}$ and conductivity were measured. The experiment run lasted for 630 hours.

\subsection{Neural Network Application for the Sacrificial Anode Protection System}

The MATLAB ${ }^{\circledR}$ neural network toolbox was used for the ANN modeling. The system was used to assess the potential difference required to control sacrificial anode cathodic protection systems and to predict corrosion rate. A network with two hidden layers was used. This number is chosen randomly as the selection of the number of neurons was specified by trial and error. For the potential difference assessment, the input layer received the variables (time of exposure, $\mathrm{pH}$, conductivity, metal composition of the anode). The output layer gave the potential difference as network result.

The tan-sigmoid transformation function was used in the first hidden and in the second layer, a pure line function. The Levenberg Marquadt feed forward neural network training algorithm was used with 107 samples.

\section{Results and Discussion}

\subsection{Results}

Table 2 shows the correlation results and mean square errors using neural networks.

Figure 1 shows the bar chart chart of the mean square errors and the corresponding network structure revealing that structure 10 had the best performance.

Figure 2 Shows the plot of electrode potentials versus exposure time for the steel samples Immersed in $1 \mathrm{M} \mathrm{NaCl}$ solution and protected with different aluminium anodes. It shows that the steel sample protected with $\mathrm{Al}-\mathrm{Zn}(0.5 \%)$ $\operatorname{Sn}(0.1 \%)$ had the best performance of the three anodes throughout the experiment run.

Figure 3 shows the plot of electrode potentials versus exposure time for the steel samples immersed in $0.5 \mathrm{M} \mathrm{NaCl}$ solution. It shows that the steel sample protected with $\mathrm{Al}-\mathrm{Zn}(10 \%)-\mathrm{Sn}(0.1 \%)$ performed best of the three anodes.

Figures 4 and 5 show a comparison between the experimental and modeled potential values for the low carbon steel sample in $1 \mathrm{M} \mathrm{NaCl}$ solution.

\subsection{Discussion of Results}

\subsubsection{Effect of Exposure Time on Potential}

Within the first 72 hours of the experiment the low carbon steel samples protected with $\mathrm{Al}-\mathrm{Zn}-\mathrm{Sn}$ anodes with varying compositions gave negative potentials. The steel sample protected with $\mathrm{Al}-\mathrm{Zn}(10 \%)-\mathrm{Sn}(0.1 \%)$ had a more negative potential of up to $-0.97 \mathrm{~V}$ after about 350 hours of exposure in $1 \mathrm{M} \mathrm{NaCl}$ and $-0.73 \mathrm{~V}$ after 300 hours in $0.5 \mathrm{M} \mathrm{NaCl}$ though the anode showed some form of fluctuations possibly due to uneven corrosion[7]. The more electronegative values of low carbon steel show that the $\mathrm{Al}-\mathrm{Zn}(10 \%)-\operatorname{Sn}(0.1 \%)$ anode is corroding quite fast in $1 \mathrm{M}$ solution. However the steel sample protected $\mathrm{Al}-\mathrm{Zn}(5 \%)-\mathrm{Sn}(0.1 \%)$ had a less negative potential of $-0.87 \mathrm{~V}$ after 350 hours of exposure, implying that the anode is not corroding as fast as that containing $10 \% \mathrm{Zn}$ and hence a better anode material in $1 \mathrm{M} \mathrm{NaCl}$ solution and that with $5 \% \mathrm{Zn}$ performing better in $0.5 \mathrm{M} \mathrm{NaCl}$. 
Table 2. Correlation and MSE for different Network Structures

\begin{tabular}{|c|c|c|c|c|c|c|c|}
\hline \multirow{2}{*}{} & \multirow{2}{*}{ No. of Iterations } & \multicolumn{2}{|c|}{ Correlation Coefficient(R-Value) } & \multicolumn{3}{c|}{ Mean Square Error (MSE) e-2 } \\
\cline { 3 - 7 } & & Training & Validation & Testing & Training & Validation & Testing \\
\hline $2-5-1$ & 24 & 0.800092 & 0.811596 & 0.770030 & 3.83112 & 5.85046 & 4.33157 \\
\hline $2-10-1$ & 11 & 0.771729 & 0.742407 & 0.861787 & 4.78746 & 4.07154 & 2.75595 \\
\hline $2-15-1$ & 48 & 0.846507 & 0.717939 & 0.798170 & 3.73605 & 5.19064 & 5.46547 \\
\hline $2-20-1$ & 22 & 0.798150 & 0.766909 & 0.851286 & 3.20208 & 8.20451 & 3.01428 \\
\hline $3-5-1$ & 13 & 0.817244 & 0.796208 & 0.772418 & 2.90510 & 8.69564 & 4.36268 \\
\hline $3-10-1$ & 19 & 0.797581 & 0.813279 & 0.812208 & 3.66967 & 5.19056 & 3.79440 \\
\hline $3-15-1$ & 9 & 0.828406 & 0.813750 & 0.729404 & 4.26745 & 3.19910 & 3.67971 \\
\hline $3-20-1$ & 10 & 0.831410 & 0.804441 & 0.754775 & 3.55374 & 4.62663 & 4.72951 \\
\hline $4-5-1$ & 13 & 0.776210 & 0.817973 & 0.846558 & 3.99940 & 4.71449 & 3.77262 \\
\hline $4-10-1$ & 9 & 0.799574 & 0.840233 & 0.850602 & 4.51663 & 2.61294 & 2.75250 \\
\hline $4-15-1$ & 17 & 0.800274 & 0.809670 & 0.823734 & 3.61581 & 3.62052 & 3.79745 \\
\hline $4-20-1$ & 21 & 0.819010 & 0.809670 & 0.823734 & 3.61581 & 3.62052 & 3.79745 \\
\hline
\end{tabular}

\subsubsection{ANN Modeling Results}

From the results of the performance of twelve network structures are presented in table 2 and fig 1 it is evident that of all twelve structures used the 4-10-1 structure had the best R-value for test data set $(0.850602)$, training data set (0.0799574), and validation data set $(0.840233)$. The accuracy of this prediction is further indicated by the low mean square error (MSE) which ranged from 0.0261294 to 0.0451663 . The number of iterations for the five structures ranged from 9 to 24 .

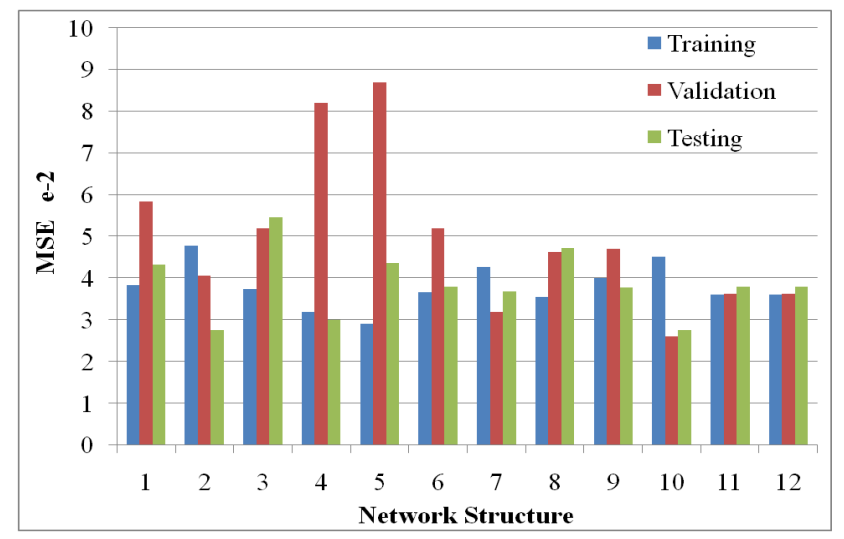

Figure 1. Plot of Mean Square Error (MSE) Vs Network Structure

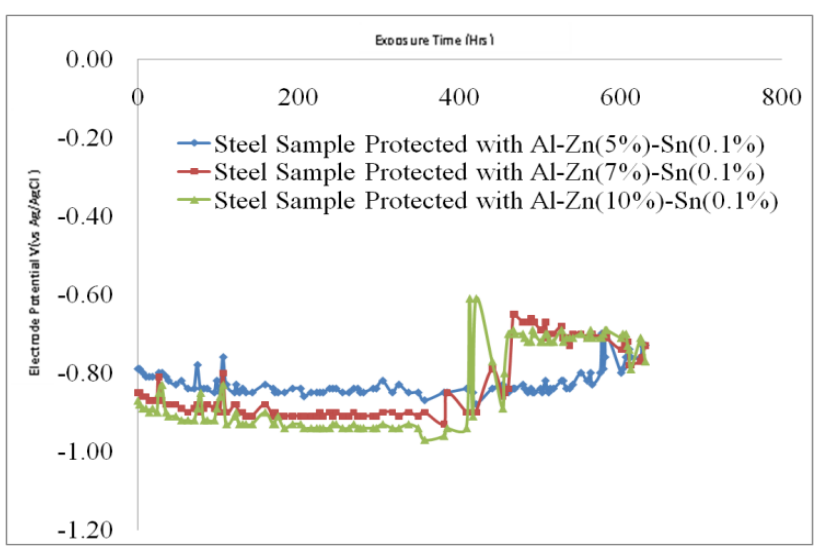

Figure 2. Plot of Electrode Potentials versus Exposure Time for Low Carbon Steels Immersed in $1 \mathrm{M} \mathrm{NaCl}$ solution

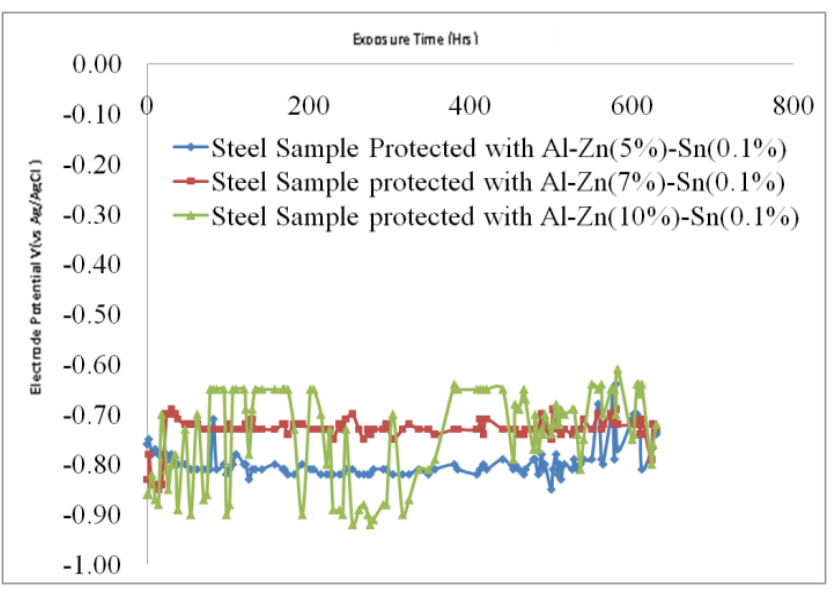

Figure 3. Plot of Electrode Potentials versus Exposure Time for Low Carbon Steels Immersed in $0.5 \mathrm{M} \mathrm{NaCl}$ solution

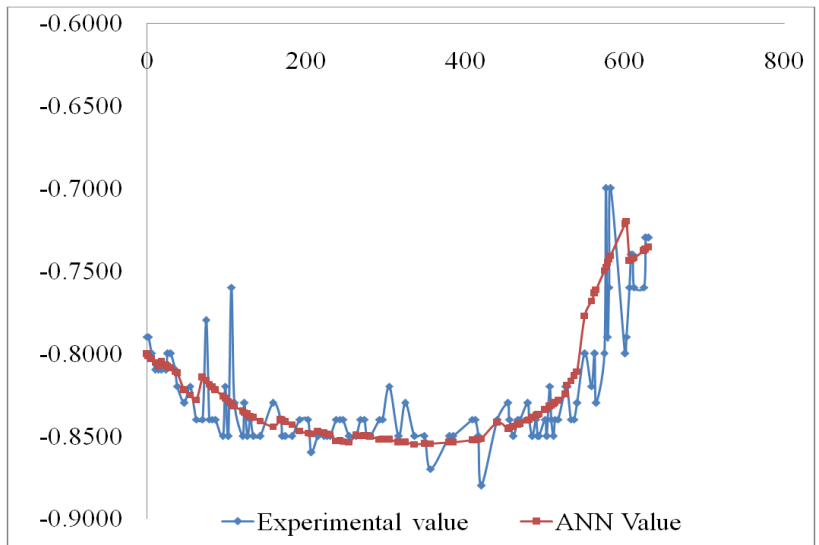

Figure 4. ANN Modeling results compared with Experimental Results for steel protected with $\mathrm{Al}-\mathrm{Zn}(5 \%)-\mathrm{Sn}(0.1 \%)$ anode in $1 \mathrm{M} \mathrm{NaCl}$

The 4-10-1 structure which was chosen as the one with the best predictive ability converged in nine (9) iterations with four (4) variables in its input layer ten (10) number of neurons in the hidden layer and an output layer. The structure was so selected as the R-value of a network reflects the ability of a network to predict well[6] i.e. its value should be as close to unity (1) as possible. Hence more importance is attached to the R-value than to the speed of the network in making the prediction. 


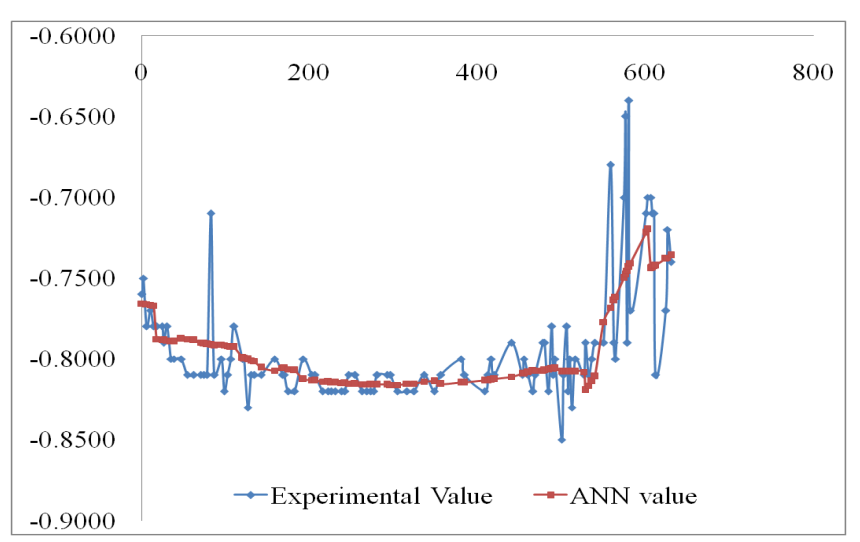

Figure 5. ANN Modeling results compared with Experimental Results for steel protected with $\mathrm{Al}-\mathrm{Zn}(5 \%)-\mathrm{Sn}(0.1 \%)$ anode in $0.5 \mathrm{M} \mathrm{NaCl}$

\section{Conclusions}

Based on the experimental data this work has shown that;

1) An effective neural network model for an Al-Zn-Sn sacrificial anode system was created using a standard commercial package with nearly all the trends noticed in the experimental data captured by the network.

2) Artificial neural networks can be used to predict quite accurately the corrosion potential of low carbon steel in saline media.

3) There is a need to conduct further experiments, use a larger data set and apply other neural network techniques to test their performance over the Levenberg Marquadt technique.

\section{REFERENCES}

[1] Roberge P.R. (1999). Handbook of Corrosion Engineering.McGrawHill, New York.

[2] http://defensenews-updates.blogspot.com/2010/01/nace-corr osion-2010-to-deliver-problem.html retrieved 2010.

[3] Adey, R.A., Yang P.A (2004).Computer Simulation as an aid to Corrosion control and Reduction.BEASY systems UK..

[4] Jalili, S., Jaberi, A., Malijani, M.G and Jafarian, M. (2008).Prediction of Lead Corrosion Behaviour using Feed
Forward Artificial Neural Network. Journal of Iranian Chemical Society, 5(4):669-676

[5] Srinivasa, P, Mathew, M.T, Stack, M.M, Roche, L.A. (2008). Some Thoughts on Neural Network Modelling of Microabrasion Corrosion process. Tribology International, 41:672 680

[6] Demuth, H., Beale, M., Martin, H., (2010).Neural Network Toolbox.Mathworks Inc.USA, pp 5-9, 5-18

[7] Emamy, M., Keyvan, A., Mahta, M., Campbell, J. (1999). Effect of Oxide Inclusions on Electrochemical Properties of Aluminium Sacrificial Anodes. Journal of Material Sciences Technology, 25(1).

[8] Srdjan ,N., Magnus ,M., Nigel ,M/, Miran, V. (2001). Probabilistic Modeling of $\mathrm{CO}_{2}$ corrosion laboratory data using neural networks. Elsevier Journal of Corrosion Science vol 43, pp 1373-1392.

[9] Yu Sun, Weidong Zenga, Yuanfei Hana, Yongqing Zhaob, Gui Wangc, Matthew, S., Darguschc, Ping Guob (2011). Modeling the correlation between microstructure and the properties of the Ti-6Al-4V alloy based on an artificial neural network. Elsevier Journal of Materials Science and Engineering A 528 (2011) 8757-8764.

[10] Tomislav Rolich, Iva Rezic', Lidija C' urkovic' (2009). Estimation of steel guitar strings corrosion by artificial neural network. Elsevier Journal of Corrosion Science 52 (2010) 996-1002.

[11] Mst Kamrunnahar, Mirna Urquidi-Macdonald (2010). Prediction of corrosion behaviour of Alloy 22 using neural network as a data mining tool. Elsevier Journal of Corrosion Science 53 (2011) 961-967.

[12] Mst Kamrunnahar, Mirna Urquidi-Macdonald (2009). Prediction of corrosion behavior using neural network as a data mining tool. Corrosion Science 52 (2010) 669-677.

[13] Birbilis, N., Cavanaugh, M.K., Sudholz, A.D., Zhu , S.M., Easton , M.A., Gibson, M.A. (2010). A combined neural network and mechanistic approach for the prediction of corrosion rate and yield strength of magnesium-rare earth alloys. Elsevier Journal of Corrosion Science 53 (2011) 168-176.

[14] Cavanaugh, M.K., Buchheit, R.G., Birbilis, N (2010). Modeling the environmental dependence of pit growth using neural network approaches. Elsevier Journal of Corrosion Science 52 (2010) 3070-3077 